\title{
Qualidade microbiológica da carne de frango comercializada na cidade de Barretos, SP
}

\author{
Microbiological quality of chicken meat marketed in the city of \\ Barretos - SP
}

Fernando Henrique Pimenta de Moura ${ }^{1 *}$, Emanuelly Calatroia Silva ${ }^{1}$, Rebeca Garcia Lemes $^{1}$,
Patricia Amoroso de Andrade ${ }^{2}$

${ }^{1}$ Curso de Zootecnia do Centro Universitário da Fundação Educacional de Barretos, Barretos - SP; *Bolsa: Programa de Iniciação científica do CNPq/PIBIC

${ }^{2}$ Prof $^{\mathrm{a}}$. Dr ${ }^{\mathrm{a}}$. do Centro Universitário da Fundação Educacional de Barretos, SP.

\begin{abstract}
Resumo
A carne de frango, por ser um produto saudável e de baixo custo é muito consumida pelo mundo todo, porém o manejo incorreto pode causar a contaminação por Salmonella sp. e outros micro-organismos. A contaminação do animal e das carcaças ocorre nas etapas de produção e abate. Para minimizar a ocorrência de doenças e patógenos relacionados ao consumo de alimentos e melhorar a qualidade é essencial a aplicação de boas práticas de manejo higiênico-sanitário. A inexistência de controle zootécnico pode afetar a produção e qualidade do produto, ocorrendo perdas de lucros. Neste trabalho foram utilizadas 34 amostras de coxa de frango comercializados na região de Barretos, SP, com objetivo de determinar sua qualidade microbiológica quanto aos parâmetros: coliformes totais, coliformes fecais, coliformes termotoloerantes, Escherichia coli, Staphylococcus aureus, Salmonella sp., Enterococcus sp., Pseudomonas sp. e fungos, que foram determinados segundo a metodologia, adaptada, de Penteado e Esmerino. Das amostras analisadas, todas foram positivas para Staphylococcus aureus. Quanto à análise microbiológica de coliformes totais, coliformes fecais, coliformes termotoloerantes, Salmonella sp., Enterococcus sp., Pseudomonas sp. e fungos, a maioria das amostras estava com contagem acima do limite permitido pela legislação, sendo que estas amostras não apresentaram Escherichia coli. Desse modo, conclui-se que a maioria das amostras de frango analisadas apresentam-se em desacordo com os limites de contaminantes estabelecidos pela legislação, não respeitando as boas práticas de manejo higiênico-sanitário. Portanto, podem ser um risco para a saúde do consumidor, uma vez que estes micro-organismos são potenciais causadores de intoxicações alimentares.
\end{abstract}

Palavras-chave: Microbiologia; Salmonella sp.; Contaminação de carne; Produção animal.

\begin{abstract}
Chicken meat, being a healthy and low-cost product, is widely consumed all over the world, but the incorrect handling can cause contamination by Salmonella sp. and other microorganisms. Contamination of the animal and carcasses occurs in the production and slaughter stages. In order to minimize the occurrence of diseases and pathogens related to food consumption and to improve quality, it is essential to apply good hygiene and sanitary management practices. The lack of zootechnical control can affect the production and quality of the product, with loss of profits. In this work, 34 samples of chicken thighs commercialized were used in the region of Barretos, state of São Paulo, in order to determine their microbiological quality as to the following parameters: Total coliforms, fecal coliforms, thermoliferating coliforms, Escherichia coli, Staphylococcus aureus, Salmonella sp., Enterococcus sp., Pseudomonas sp. and Fungi, which were determined according to the methodology, adapted, by Penteado and Esmerino. Of the analyzed samples, all were positive for Staphylococcus aureus. Regarding the microbiological analysis of total coliforms,
\end{abstract}

Autor para correspondência: Fernando Henrique Pimenta de Moura - Av. Prof. Roberto Frade Monte, 389 - CEP: 14783-226 - Barretos (SP) E-mail:fernandohpmoura@gmail.com

Recebido em: 19 de novembro de 2019

Aceito para publicação: 28 de março de 2020

https://doi.org/10.4322/1980-0029.112020 
fecal coliforms, thermotolerant coliforms, Salmonella sp., Enterococcus sp., Pseudomonas sp. and fungi, most of the samples were counted above the limit allowed by the legislation, being only negative for the presence of Escherichia coli. Thus, it is possible to conclude that the majority of chicken samples analyzed were in disagreement with the limits of contaminants established by the legislation, not respecting the good practices of hygienic-sanitary management. Therefore, they can be a risk to the consumer's health, since these microorganisms are potential causes of food poisoning.

Keywords: Microbiology; Salmonella sp.; Contamination of meat; Animal production.

\section{Introdução}

A carne de frango, por ser um produto saudável e de baixo custo é muito consumida pelo mundo todo. Dessa forma, sua qualidade microbiológica e o estudo da ocorrência de micro-organismos patogênicos tornaram-se importantes para a saúde pública. Portanto é essencial que a carne de frango apresente uma contagem bacteriana baixa e a identificação de bactérias e/ou indicadores de condições higiênico-sanitárias devem contribuir para a confirmação da qualidade (Silva et al., 2002).

Programas de segurança alimentar devem garantir um controle ativo em toda a cadeia produtiva desde a produção, armazenamento e distribuição, ou até mesmo no consumo do alimento in natura ou processado. Tais programas têm como objetivo principal aumentar a segurança e a qualidade dos alimentos produzidos, ampliar a exportação, preparar o setor produtivo brasileiro para atender as exigências dos países importadores, em termos de segurança dos alimentos e aumentar a competitividade nas empresas (Cardoso \& Tessari, 2008).

A contaminação por micro-organismos pode ocorrer durante algumas etapas da cadeia de produção nas quais as condições higiênico-sanitárias e de conservação são deficientes. Esta contaminação geralmente ocorre nos cortes e carcaças a partir de equipamentos, utensílios e ambiente em condições insatisfatórias de higiene, durante os estágios de abate, armazenamento, transporte e manipulação (Montezani et al., 2017).

São constantemente isoladas Salmonella spp, Staphylococcus aureus e Escherichia coli, presumíveis causadores de danos à saúde e de toxinfecções alimentares, além de micro-organismos relacionados à deterioração da carne, tais como Pseudomonas sp. (Spoto et al., 1999; Miyagusku et al., 2003).

Dentre os patógenos disseminados na avicultura, destacam-se Salmonella spp. e Staphylococcus aureus e a relevância da disseminação destes patógenos vem sendo muito estudada na cadeia produtiva das aves (Tessari et al. 2008; Montezani et al., 2017).

A presença da Salmonella spp no sistema digestório das aves facilita a colonização das carcaças de frango durante os estágios de abate, ao mesmo tempo que Staphylococcus aureus é capaz infectar os cortes e carcaças a partir da pele e das vias respiratórias de manipuladores de alimentos e dos frangos vivos. Caso a carne seja preservada em condições insatisfatórias de conservação, o número inicial de Staphylococcus aureus será capaz de multiplicar-se e produzir toxinas termoestáveis responsáveis por toxinfecção em seres humanos (Montezani et al., 2017).

A fiscalização da Salmonella spp na avicultura inclui procedimentos não só na indústria, mas também no campo, buscando diminuir a contagem da bactéria no sistema digestório das aves. Boas práticas no preparo da carne de frango pelos consumidores são fundamentais para a prevenção da salmonelose. Isto passou a ser melhorado com o acolhimento de políticas de controle e prevenção da Salmonella spp em toda a cadeia avícola. Tendo-se em conta a atuação de aves no contágio de humanos, foi criado o Programa Nacional de Sanidade Avícola (PNSA) pelo Ministério da Agricultura, Pecuária e Abastecimento (Portaria nº193/1994), com adoção de normas (Portaria nº/1995) para prevenção e controle de Salmonella spp em aves (Cardoso \& Tessari, 2008).

É recomendado que haja cuidado com o manuseio e armazenamento das rações e insumos para as aves, também simultaneamente manter sempre limpo o ambiente em que elas são criadas e os plantéis reprodutores, para se evitar disseminação de patógenos. Quanto aos produtos de origem avícola, recomenda-se que no caso do ovo devese mantê-lo refrigerado $\left(4\right.$ a $\left.7^{\circ} \mathrm{C}\right)$ até a hora do consumo, sempre os lavar com sanitizantes e não comercializá-los com mais de duas semanas, pois ocorre deterioração da estrutura interna do ovo, podendo contaminá-lo por conta da troca gasosa 
da casca com o ambiente externo (Cardoso \& Tessari, 2008).

Quanto à carne de frango, é comprovado que um pequeno número de animais infectados pode contaminar todos os outros no abatedouro, representando uma ameaça à saúde pública em eventos nos quais as carcaças não são processadas corretamente. É relevante ressaltar que a manipulação destes alimentos exerce papel importante na propagação da bactéria, por proporcionar contaminação cruzada no ambiente de preparo de outros alimentos. Se a bactéria encontrar nutrientes e condições favoráveis, como $\mathrm{pH}$, atividade da água e temperatura, poderá propagar-se rapidamente. Sendo assim, é essencial o cozimento das carnes e ovos e higienização dos utensílios utilizados adequadamente (Cardoso \& Tessari, 2008).

Diante do exposto, o objetivo desta pesquisa foi avaliar e determinar a qualidade microbiológica da carne de frango comercializada na cidade de Barretos, SP, quanto aos parâmetros microbiológicos: coliformes totais, coliformes termotolerantes, Staphylococcus aureus, Salmonella sp., Enterococcus spp, Escherichia coli, Pseudomonas spp e fungos.

\section{Material e métodos}

As 34 amostras de cortes comerciais de coxa de frangos foram obtidas de diversos pontos de venda localizados no município de Barretos, SP.

Foram coletadas amostras de três marcas diferentes e após quatro semanas, amostras destas mesmas marcas foram novamente coletadas nos respectivos pontos. Cada lote foi levado ao refrigerador a $10^{\circ} \mathrm{C}$ e embalado em bandejas de isopor com no máximo cinco unidades do produto. As unidades foram analisadas individualmente $\mathrm{e}$ no total foram efetuadas análises em duplicata. A coleta seguiu as orientações estabelecidas na Resolução RDC ANVISA n ${ }^{\circ} 12$, de 2 de janeiro de 2001 (Brasil, 2001).

A técnica utilizada foi de lavagem superficial com $300 \mathrm{~mL}$ de água peptonada. O caldo de lavagem foi utilizado para as análises microbiológicas e considerado como sendo sem diluição (100). Na sequência, diluições decimais foram realizadas em água peptonada tamponada estéril até a diluição $10^{-5} \mathrm{e}$ as análises microbiológicas foram realizadas segundo Silva et al. (2007).
A contagem de fungos (UFC/g) seguiu a metodologia das normas internacionais da APHA (American Public Health Association, 1992). A amostra (caldo de lavagem) foi semeada em profundidade, $1 \mathrm{~mL}$ de cada diluição decimal seriada, em duplicata, utilizando o ágar batata dextrose (BDA) acidificado com ácido tartárico $10 \%$ até pH 3,5. A incubação das placas de Petri contendo as amostras ocorreu em estufa bacteriológica a $35-37^{\circ} \mathrm{C}$, por 48 horas, e a $25^{\circ} \mathrm{C}$, por cinco dias, para os testes de número mais provável (NMP) e contagem de bolores e leveduras, respectivamente.

Para a quantificação de Staphylococcus aureus (UFC/g) foi utilizado o ágar Baird Parker (BP) (diluições de $10^{-1}$ a $10^{-6}$ ). A incubação ocorreu em estufa bacteriológica a $35-37^{\circ} \mathrm{C}$, por 48 horas, e a $37^{\circ} \mathrm{C}$, por três dias. A confirmação de $S$. aureus foi realizada com a prova da coagulase em tubo segundo Silva et al. (2007).

Para a determinação de coliformes totais, coliformes fecais ou termotolerantes $\left(45^{\circ} \mathrm{C}\right)$ utilizou-se o método do número mais provável (NMP). Para esses micro-organismos foram realizados os testes presuntivo e confirmatório. Os resultados positivos foram comparados com os dados de uma tabela com limite de confiança de $95 \%$ para a enumeração do número mais provável por grama da amostra (NMP/g).

$\mathrm{Na}$ contagem de Escherichiacoli, os caldos EC (E.C. Broth) (incubados a $45^{\circ} \mathrm{C}$ ) positivos foram repicados em ágar eosina azul de metileno (EMB) e a identificação foi realizada por meio de provas bioquímicas com a utilização do Manual de Identificação de Enterobactérias NEWPROV. Para identificação, foi trabalhado com uma probabilidade de $90 \%$.

Para a pesquisa de Salmonella spp, o caldo de lavagem foi incubado em estufa a $35^{\circ} \mathrm{C}$ por 24 horas para o pré-enriquecimento, de acordo com Machado et al. (1988). Após a incubação, alíquotas de 5,0 $\mathrm{mL}$, em duplicata, foram transferidas para $45 \mathrm{~mL}$ de Caldo Tetrationato e as misturas obtidas foram incubadas a $35^{\circ} \mathrm{C}$ por 18-24 horas, para enriquecimento seletivo. Após a incubação as culturas foram semeadas com alça, por esgotamento em duplicata, nos meios de ágar Salmonella-Shigella (SS) e ágar xilose lisina desoxicolato (XLD). Colônias suspeitas foram inoculadas em uma série bioquímica para enterobactérias NEWPROV e no ágar tríplice açúcar ferro (TSI). Cepas com reações sugestivas foram 
submetidas à confirmação por meio de prova de soroaglutinação com soro polivalente somático PROBAC (Caramori Júnior et al., 2005). Como controle de qualidade foi utilizada uma cepa de referência: Salmonella typhimurium ATCC 14028.

Na pesquisa de Enterococcus spp foi seguido o método dos tubos múltiplos ou NMP. Amostras positivas no teste presuntivo foram submetidas ao teste confirmatório. Assim, cada tubo positivo em Caldo Dextrose Azida foi semeado em placa contendo ágar bile esculina e em caldo com $6,5 \%$ de $\mathrm{NaCl}$. As placas e tubos foram incubados a $35^{\circ} \mathrm{C}$ durante 24 horas. Os enterococos são tolerantes ao sal e crescem no caldo com $6,5 \% \mathrm{NaCl}$. No ágar bile esculina o crescimento dos enterococos indica resistência à bile e o escurecimento do meio indica hidrólise da esculina (Silva, et al., 2007). Para identificação de Enterococcus faecalis foram realizadas provas bioquímicas específicas (Oplustil et al., 2004).

Na pesquisa de Pseudomonas spp foi utilizado o ágar cetrimida. As colônias características de Pseudomonas aeruginosa (verde-azulada e fluorescente) e de Pseudomonas fluorescens (amarela, esverdeada, fluorescente) foram consideradas como prova positiva presuntiva da presença das mesmas.

\section{Resultados}

Os resultados das análises microbiológicas das amostras de cortes comerciais de coxa de frangos do município de Barretos, SP, apresentaram altas contagens de Staphylococcus spp. Foram encontradas amostras positivas para Salmonella spp, Pseudomonas spp, Enterococcus sp, Staphylococcus aureus e fungos (Tabela 1). As amostras analisadas foram negativas para a presença de Escherichia coli. Todas as amostras de coliformes totais e termotolerantes foram positivas (Tabela 2).

\section{Discussão}

Em nossa pesquisa, todas as amostras foram positivas para fungos. Esses resultados foram superiores e diferentes aos de Saccomori (2013), que estudou fungos deteriorantes de empanados congelados de frango e determinaram crescimento de fungos filamentosos nas sete amostras de frango empanado congelado em dois diferentes meios. Fungos ocasionam alterações no sabor, odores e na qualidade dos alimentos (Diniz, 2002). Alguns gêneros de fungos podem se desenvolver e produzir micotoxinas, tornando-se graves riscos à saúde humana e animal (Bennett $\&$ Klich, 2003).

$\mathrm{Na}$ análise microbiológica foi verificada a presença de Staphylococcus aureus em todas as amostras analisadas, com contagens variando entre $1,7 \times 10^{1} \mathrm{e}>1,0 \times 10^{3} \mathrm{UFC} / \mathrm{g}$ (Tabela 1 ). A legislação brasileira considera aceitável a contagem de $S$. aureus até $10^{3} \mathrm{UFC} / \mathrm{g}$ do alimento (Brasil, 2001). Assim, apenas duas amostras analisadas estavam adequadas para o consumo. Silva \& Menão (2016) encontraram Staphylococcus spp em coxa e sobrecoxa de frangos com contagens entre $1 \times 10^{3}$ e $2 \times 10^{7} \mathrm{UFC} / \mathrm{g}$, sendo uma das amostras negativa para o isolamento da bactéria. Destas amostras analisadas, três foram identificadas como $S$. aureus, diferente do presente trabalho, em que $100 \%$ das amostras de frango analisadas foram identificadas com S. aureus. Esmerino \& Penteado (2010) avaliaram a qualidade microbiológica da carne de frango comercializada no município de Ponta Grossa, Paraná, e observaram que 40\% das amostras analisadas foram positivas para Staphylococcus aureus, com contagens variando entre 11 e $47 \mathrm{UFC/g}$, sendo consideradas baixas pela Comissão Nacional de Normas e Padrões para Alimentos (CNNPA). Freitas et al. (2006) analisaram cepas de Staphylococcus spp isoladas de carcaças de frango comercializadas na cidade do Recife, PE, e obtiveram contagens baixas de Staphylococcus aureus, de $10^{1}$ a $10^{2} \mathrm{UFC} / \mathrm{g}$ em carcaças de frango resfriadas, sendo valores inferiores ao observado no atual trabalho. Ainda na cidade de Recife, Freitas et al. (2004) analisaram a ocorrência de Staphylococcus aureus em carcaças de frango e encontraram contaminação na maioria dos cortes de frango, assim como nesta pesquisa (Tabela 1). Freitas et al. (2004) constaram que 58 $(91,1 \%)$ das carcaças de frango foram positivas para Staphylococcus spp, sendo que 40 das carcaças $(65,0 \%)$ eram Sthaphylococcus aureus e 18 (31,0\%), Staphylococcus coagulase.

Brito et al. (2010) detectaram Staphylococcus coagulase e micro-organismos mesófilos em carcaças de frango in natura e constataram que as 40 amostras de carcaças de frango in natura analisadas estavam contaminadas por Staphylococcus coagulase, sendo a contagem máxima de $10^{7} \mathrm{UFC} / \mathrm{g}$. Montezani et al. (2017) isolaram Salmonella spp e Staphylococcus aureus de 70 amostras de carne de frango de estabelecimentos comerciais no município de Tupã, SP, e detectaram Staphylococcus aureus 
Tabela 1. Média de unidades formadoras de colônias (UFC) de Salmonella sp, Staphylococcus aureus, Enterococcus spp, Escherichia coli, Pseudomonas e Fungos.

\begin{tabular}{|c|c|c|c|c|c|c|}
\hline Amostra & $\begin{array}{c}\text { Staphylococcus } \\
\text { aureus } \\
\text { UFC/g }\end{array}$ & $\begin{array}{c}\text { Presença de } \\
\text { Salmonella sp. } \\
\text { UFC/g }\end{array}$ & $\begin{array}{c}\text { Enterococcus sp. } \\
\text { NMP/g }\end{array}$ & $\begin{array}{c}E . \text { coli } \\
\mathrm{NMP} / \mathrm{g}\end{array}$ & $\begin{array}{c}\text { Presença de } \\
\text { Pseudomona sp. }\end{array}$ & $\begin{array}{l}\text { Fungos } \\
\text { UFC/g }\end{array}$ \\
\hline 1 & $>1,0 \times 10^{3}$ & + & $>1,0 \times 10^{2}$ & - & + & $>1,0 \times 10^{2}$ \\
\hline 2 & $>1,0 \times 10^{3}$ & + & $>1,0 \times 10^{2}$ & - & + & $>1,0 \times 10^{2}$ \\
\hline 3 & $>1,0 \times 10^{3}$ & + & $>1,0 \times 10^{2}$ & - & + & $>1,0 \times 10^{2}$ \\
\hline 4 & $>1,0 \times 10^{3}$ & + & $>1,0 \times 10^{2}$ & - & + & $>1,0 \times 10^{2}$ \\
\hline 5 & $>1,0 \times 10^{3}$ & + & $>1,0 \times 10^{2}$ & - & + & $>1,0 \times 10^{2}$ \\
\hline 6 & $>1,0 \times 10^{3}$ & + & $>1,0 \times 10^{2}$ & - & + & $>1,0 \times 10^{2}$ \\
\hline 7 & $>1,0 \times 10^{3}$ & + & $>1,0 \times 10^{2}$ & - & + & $>1,0 \times 10^{2}$ \\
\hline 8 & $1,7 \times 10^{1}$ & + & $2,5 \times 10^{1}$ & - & + & $0,7 \times 10^{1}$ \\
\hline 9 & $>1,0 \times 10^{3}$ & + & $>1,0 \times 10^{2}$ & - & + & $>1,0 \times 10^{2}$ \\
\hline 10 & $>1,0 \times 10^{3}$ & + & $>1,0 \times 10^{2}$ & - & + & $>1,0 \times 10^{2}$ \\
\hline 11 & $>1,0 \times 10^{3}$ & + & $>1,0 \times 10^{2}$ & - & + & $>1,0 \times 10^{2}$ \\
\hline 12 & $1,9 \times 10^{1}$ & + & $1,8 \times 10^{1}$ & - & + & $0,5 \times 10^{1}$ \\
\hline 13 & $>1,0 \times 10^{3}$ & + & $>1,0 \times 10^{2}$ & - & + & $>1,0 \times 10^{2}$ \\
\hline 14 & $>1,0 \times 10^{3}$ & + & $>1,0 \times 10^{2}$ & - & + & $>1,0 \times 10^{2}$ \\
\hline 15 & $>1,0 \times 10^{3}$ & + & $>1,0 \times 10^{2}$ & - & + & $>1,0 \times 10^{2}$ \\
\hline 16 & $>1,0 \times 10^{3}$ & + & $>1,0 \times 10^{2}$ & - & + & $>1,0 \times 10^{2}$ \\
\hline 17 & $>1,0 \times 10^{3}$ & + & $>1,0 \times 10^{2}$ & - & + & $>1,0 \times 10^{2}$ \\
\hline 18 & $>1,0 \times 10^{3}$ & + & $>1,0 \times 10^{2}$ & - & + & $>1,0 \times 10^{2}$ \\
\hline 19 & $>1,0 \times 10^{3}$ & + & $>1,0 \times 10^{2}$ & - & + & $>1,0 \times 10^{2}$ \\
\hline 20 & $>1,0 \times 10^{3}$ & + & $>1,0 \times 10^{2}$ & - & + & $>1,0 \times 10^{2}$ \\
\hline 21 & $>1,0 \times 10^{3}$ & + & $>1,0 \times 10^{2}$ & - & + & $>1,0 \times 10^{2}$ \\
\hline 22 & $>1,0 \times 10^{3}$ & + & $>1,0 \times 10^{2}$ & - & + & $>1,0 \times 10^{2}$ \\
\hline 23 & $>1,0 \times 10^{3}$ & + & $>1,0 \times 10^{2}$ & - & + & $>1,0 \times 10^{2}$ \\
\hline 24 & $>1,0 \times 10^{3}$ & + & $>1,0 \times 10^{2}$ & - & + & $>1,0 \times 10^{2}$ \\
\hline 25 & $>1,0 \times 10^{3}$ & + & $>1,0 \times 10^{3}$ & - & + & $>1,0 \times 10^{2}$ \\
\hline 26 & $>1,0 \times 10^{3}$ & + & $>1,0 \times 10^{3}$ & - & + & $>1,0 \times 10^{2}$ \\
\hline 27 & $>1,0 \times 10^{3}$ & + & $>1,0 \times 10^{3}$ & - & + & $>1,0 \times 10^{2}$ \\
\hline 28 & $>1,0 \times 10^{3}$ & + & $>1,0 \times 10^{3}$ & - & + & $>1,0 \times 10^{2}$ \\
\hline 29 & $>1,0 \times 10^{4}$ & + & $>1,0 \times 10^{2}$ & - & + & $>1,0 \times 10^{2}$ \\
\hline 30 & $>1,0 \times 10^{3}$ & + & $>1,0 \times 10^{2}$ & - & + & $>1,0 \times 10^{2}$ \\
\hline 31 & $>1,0 \times 10^{3}$ & + & $>1,0 \times 10^{2}$ & - & + & $>1,0 \times 10^{2}$ \\
\hline 32 & $>1,0 \times 10^{3}$ & + & $>1,0 \times 10^{2}$ & - & + & $>1,0 \times 10^{2}$ \\
\hline 33 & $>1,0 \times 10^{3}$ & + & $>1,0 \times 10^{2}$ & - & + & $>1,0 \times 10^{2}$ \\
\hline 34 & $>1,0 \times 10^{3}$ & + & $>1,0 \times 10^{2}$ & - & + & $>1,0 \times 10^{2}$ \\
\hline
\end{tabular}

+ presença; - ausência.

em 10 amostras (14,2\%). No entanto, somente 4,2\% eram caracterizadas como S. coagulase - positivas, com contagens de $7,28 \times 10^{3}, 1,88 \times 10^{4}$ e $1,6 \times 10^{3}$ $\mathrm{UFC} / \mathrm{g}$. Comparando com a literatura, as amostras de carne de frango analisadas em nossa pesquisa apresentaram elevada contaminação por $S$. aureus. Sua alta contagem ocorre devido a falhas na higiene e no processo de abate (Azevedo et al., 2005). A falta de refrigeração das carcaças por períodos longos também determina elevadas contagens de Staphylococcus spp (Pereira et al., 1999).
Neste trabalho foram encontrados coliformes totais em $100 \%$ das amostras, bem como em termotolerantes (Tabela 2). Esses micro-organismos são indicadores sanitários e uma vez presentes, pode-se inferir que outros patógenos podem ser encontrados. A legislação brasileira estabelece apenas a contagem de coliformes termotolerantes como padrão microbiológico para carcaças de frango congeladas ou resfriadas, considerando como limite máximo o valor de $10^{4} \mathrm{UFC} / \mathrm{g}$ (Brasil, 2001) e, para essa análise, todas as amostras 
Tabela 2. Número mais provável (NMP) de coliformes totais e termotolerantes $\left(45^{\circ} \mathrm{C}\right)$.

\begin{tabular}{|c|c|c|}
\hline $\begin{array}{l}\text { Amostras } \\
\text { de carne de } \\
\text { frango }\end{array}$ & $\begin{array}{l}\text { Coliformes } \\
\text { totais (NMP/g) }\end{array}$ & $\begin{array}{c}\text { Termotolerantes } \\
\text { a } 45^{\circ} \mathrm{C} \\
\text { (NMP/g) }\end{array}$ \\
\hline 1 & 14 & 9,4 \\
\hline 2 & 20 & 16 \\
\hline 3 & 27 & 11 \\
\hline 4 & 11 & 20 \\
\hline 5 & 36 & 23 \\
\hline 6 & 20 & 15 \\
\hline 7 & 29 & 20 \\
\hline 8 & 23 & 11 \\
\hline 9 & 7,2 & 11 \\
\hline 10 & 9,4 & 14 \\
\hline 11 & 6,2 & 9,4 \\
\hline 12 & 35 & 29 \\
\hline 13 & 15 & 23 \\
\hline 14 & 11 & 14 \\
\hline 15 & 21 & 16 \\
\hline 16 & 20 & 20 \\
\hline 17 & 29 & 36 \\
\hline 18 & 23 & 20 \\
\hline 19 & 14 & 16 \\
\hline 20 & 27 & 23 \\
\hline 21 & 3,0 & 6,2 \\
\hline 22 & 20 & 21 \\
\hline 23 & 16 & 28 \\
\hline 24 & 11 & 16 \\
\hline 25 & 20 & 21 \\
\hline 26 & 15 & 20 \\
\hline 27 & 3,0 & 7,2 \\
\hline 28 & 14 & 21 \\
\hline 29 & 15 & 20 \\
\hline 30 & 11 & 16 \\
\hline 31 & 20 & 23 \\
\hline 32 & 23 & 27 \\
\hline 33 & 36 & 29 \\
\hline 34 & 29 & 21 \\
\hline
\end{tabular}

apresentaram resultados superiores ao limite permitido pela legislação, com contagens que variaram entre $1,0 \times 10^{4} \mathrm{UFC} / \mathrm{g}$ e $5,1 \times 10^{7} \mathrm{UFC} / \mathrm{g}$. Menezes et al. (2018) analisaram carcaças de frangos em Minas Gerais e demonstraram que, das 240 carcaças analisadas, foram encontrados coliformes totais em $82(34,2 \%)$ e termotolerantes em 33 (13,8\%) amostras. Pimentel et al. (2019) verificaram a qualidade microbiológica da carne de frango comercializável e os resultados mostraram que todas as amostras analisadas apresentaram contaminação por coliformes totais, com níveis que variaram de $150 \mathrm{NMP} / \mathrm{g}$ a $>1.100 \mathrm{NMP} / \mathrm{g}$. Embora a legislação não determine limites para coliformes totais, sua detecção é relevante, uma vez que estes micro-organismos estão relacionados à qualidade higiênico-sanitária dos alimentos. Pimentel et al. (2019) também verificaram coliformes termotolerantes em 4 amostras $(66,66 \%)$ com contagens variando de 150 a $1.100 \mathrm{NMP} / \mathrm{g}$, dentro dos padrões estabelecidos pela resolução vigente, a qual determina que carnes resfriadas ou congeladas, in natura, de aves (carcaças inteiras, fracionadas ou cortes) devem apresentar níveis de até $10^{4}$ $\mathrm{NMP} / \mathrm{g}$. Também, nesta pesquisa, foi constatado que todas as amostras analisadas foram positivas para coliformes totais e termotolerantes. Sales et al. (2014) avaliaram a qualidade microbiológica da carne de frango em Curitiba, PR. Similar ao nosso trabalho, observaram que das 10 amostras analisadas, $80 \%$ foram contaminadas por coliformes totais e $10 \%$ foram contaminadas por termotolerantes. Melo (2016) estudou a qualidade higiênico-sanitária de carne de frango in natura comercializada no município de Santa Cruz, RN, e, assim como em nossa pesquisa, constatou contaminação na maioria dos cortes de frango: $75 \%$ apresentaram contaminação por coliformes totais e $50 \%$ por coliformes termotolerantes. Cardoso et al. (2005) pesquisaram Salmonella spp, coliformes totais, coliformes fecais e mesófilos em carcaças e cortes de frango e constataram que $20,7 \%$ das amostras estavam em condições insatisfatórias ou impróprias para o consumo, sendo inferiores aos resultados de nosso trabalho. Esmerino \& Penteado (2010), analisando a carne de frango, verificaram que estas amostras apresentaram contaminação por coliformes totais e termotolerantes, respectivamente, de 8,0 e 4,1 x102 NMP/g, sendo inferiores ao de nossa pesquisa. Coliformes totais estão relacionadas às condições higiênicas (Delazari, 1998), sendo que altas contagens significam contaminação após processamento, higiene deficiente, temperaturas inadequadas ou multiplicação durante o processamento ou estocagem (Pardi et al., 1993).

De acordo com os resultados obtidos no presente estudo, não houve atividade microbiana para Escherichia coli. Por outro lado, Silva (2018) observou que $55 \%$ de 80 amostras de cortes de frango temperado foram positivas para $E$. coli e Salmonella sp. Casagrande (2016) realizou a quantificação de enterobactérias e Clostridium spp 
e detecção molecular de Clostridium perfringens, Escherichia coli e Salmonella spp em pontos da cadeia produtiva de carne de frango e relatou que $30 \%$ das amostras colhidas em supermercado apresentavam E. coli, resultado superior quando comparado com a presente pesquisa. Magwedere et al. (2013) estudaram a incidência de cepas de Escherichia coli produtoras de toxina Shiga em carnes varejistas de carne bovina, suína, de frango, veado, javali, bisão e coelho e encontraram contaminação na maioria das amostras, sendo positivo para $E$. coli diarreiogênicas em 75\% das amostras. Escherichia coli são bactérias Gram negativas que habitam a microbiota intestinal de animais e humanos, não sendo patogênicas. Entretanto, podem apresentar virulência que as torna capazes de causar doenças. O mal manejo no abate e armazenamento pode contaminar as carcaças e, posteriormente, chegar à mesa do consumidor contaminadas (Caldorin, et al., 2013; Trung et al., 2016).

Pimentel et al. (2019) não detectaram contaminação por Salmonella spp em nenhuma amostra avaliada, diferente do presente trabalho, que apresentou Salmonella spp em todas as amostras analisadas (Tabela 1). Menezes et al. (2018) observaram contaminação por Salmonella spp em 9,1\% das amostras em Minas Gerais, diferente deste trabalho, em que todas as amostras foram positivas para Salmonella spp (Tabela 1). Montezani et al. (2017) isolaram Salmonella spp e Staphylococcus aureus de carne de frango de estabelecimentos comerciais no município de Tupã, SP, e observaram que apenas uma amostra de corte resfriado $(1,4 \%)$ foi positiva para Salmonella $\mathrm{spp}$, diferente dos nossos resultados (Tabela 1). Similar aos resultados do presente trabalho, Lourenço \& Silva (2018) avaliaram a presença de Salmonella spp em carcaças de frango comercializadas no município de Maringá, PR, e constataram que dentre as 16 amostras analisadas, $13(81,25 \%)$ foram positivas para Salmonella spp. Zagonel et al. (2017) avaliaram a qualidade higiênico-sanitária de coxas e sobrecoxas de frango resfriadas obtidas comercialmente na região do Alto do Vale do Peixe, SC, e encontraram Salmonella spp em $100 \%$ das amostras de carne de frango resfriadas comercializadas, sendo um resultado semelhante ao encontrado neste trabalho. Silva et al. (2004) estudaram a presença de Salmonella spp em ovos e carcaças de frango in natura comercializadas em Maceió e relataram que $43 \%$ das carcaças estavam contaminadas, porcentagem menor em comparação com o presente trabalho. Esmerino \& Penteado (2010) avaliaram a qualidade microbiológica da carne de frango comercializada no município de Ponta Grossa, PR, e não detectaram contaminação por Salmonella spp. Segundo o Ministério da Agricultura, Pecuária e Abastecimento, a Instrução Normativa $n^{\circ} 20$, de 21 de outubro de 2016 (Brasil, 2016) estabelece o controle e o monitoramento de Salmonella spp nos estabelecimentos avícolas comerciais de frangos e perus de corte e nos estabelecimentos de abate de frangos, galinhas, perus de corte e reprodução registrados no Serviço de Inspeção Federal (SIF), com objetivo de reduzir a prevalência desse agente e estabelecer um nível adequado de proteção ao consumidor. Deve ocorrer ausência de Salmonella spp em vinte e cinco gramas (25g) de carne de frango (Brasil, 2001). A presença de Salmonella spp em aves é esperada quando as condições higiênico-sanitárias durante o abate e comercialização são inadequadas.

Diferente dos nossos resultados, Esmerino \& Penteado (2010) avaliaram a qualidade microbiológica da carne de frango comercializada no município de Ponta Grossa, PR, e relataram que $60 \%$ do lote apresentou Enterococcus spp, que variou de 0,3 a $16,6 \mathrm{NMP} / \mathrm{g}$. Gomes (2007) avaliou a virulência e desempenho de indicadores de higiene quanto a Enterococcus spp em amostra de alimentos e água e observou 3,8 UFC/g em peitos de frango, sendo inferior ao resultado de nossa pesquisa que apresentou Enterococcus spp em todas as amostras analisadas, o que pode ser observado na Tabela 1. Enterococcus spp são considerados indicadores de higiene e contaminação fecal, sendo comparados com Escherichia coli e outros coliformes e podem ser mais tolerantes à refrigeração, sobrevivendo por mais tempo durante a estocagem (Ingham \& Schmidt, 2000).

Em nossa pesquisa foi constatado que todas as amostras foram positivas para Pseudomonas spp, sendo o menor valor 1,5 UFC/mL. Assim como em nosso trabalho, Esmerino \& Penteado (2010) avaliaram a qualidade microbiológica da carne de frango comercializada no município de Ponta Grossa, PR, e obtiveram contaminação na maioria das amostras analisadas. Observaram que em $70 \%$ das 50 amostras analisadas e em todos os lotes pelo menos uma das amostras estava contaminada por Pseudomonas spp, semelhante ao nosso trabalho. Galarz et al. (2010) estudaram 
a curva de crescimento microbiano em produtos à base de peito de frango durante simulação da cadeia de abastecimento para filé de peito de frango cru, filé de peito de frango temperado com $\mathrm{NaCl}$ e filé de peito de frango cozido armazenados a $-18 \pm 0,5^{\circ} \mathrm{C}$, por 20 dias, e transferidos para armazenamento a $4 \pm 1^{\circ} \mathrm{C}$, por mais 21 dias e concluíram que a contagem de Pseudomonas spp, definida como indicativa de término de vida útil, é de 6 a $7 \log 10$ UFC.g $^{-1}$. As amostras mantiveram-se apropriadas para consumo até 11 a 12 dias de armazenamento a $4^{\circ} \mathrm{C}$, mostrando que após esse período a qualidade é comprometida. É de extrema importância que a carne esteja isenta desse micro-organismo, pois ele é responsável pela deterioração da carne (Miyagusku et al., 2003).

\section{Conclusão}

Conclui-se que a maioria das amostras de frango analisadas se apresentam em desacordo com os limites de contaminantes estabelecidos pela legislação. Um possível erro nas etapas da cadeia de produção, armazenamento, transporte e comercialização pode ocasionar contaminação da carcaça, indicando processamento em condições higiênico-sanitárias inadequadas. Logo, o uso de carne de frango contaminada pode constituir um sério risco para a saúde do consumidor, potencialmente causando intoxicações alimentares.

\section{Agradecimentos}

Agradecemos ao Centro Universitário da Fundação Educacional de Barretos-UNIFEB, ao CNPq pela bolsa concedida, à orientadora do projeto de pesquisa e aos colaboradores do projeto.

\section{Referências}

American Public Health Association - APHA. (1992). Standard methods for the examination of water and wastewater (pp. 4-93). Washington: APHA. Recuperado em 15 junho de 2018, de http://yabesh.ir/wp-content/uploads/2018/02/ Standard-Methods-23rd-Perv.pdf

Azevedo, A. P., Verri, M. P., \& Azevedo, R. V. P. (2005). Resistograma e fenotipagem de Staphylococcus aureus, isolado de manipuladores de alimentos. Higiene Alimentar, 19, 133-143. Recuperado em 29 junho de 2019, de https:// repositorio.usp.br/item/001449812
Bennett, J. W., \& Klich, M. (2003). Mycotoxins, 16(3), 497-516.

Brasil. Ministério da Agricultura, Pecuária e Abastecimento - MAPA. (2016, outubro 25). Instrução Normativa ${ }^{\circ} 20$, de 21 de outubro de 2016. Diário Oficial [da] República Federativa do Brasil, Brasília, Seção 1. Recuperado em 02 fevereiro de 2020, de http://www.in.gov.br/ materia/-/asset_publisher/Kujrw0TZC2Mb/content/ $\mathrm{id} / 22061817 /$ do1-2016-10-25-instrucao-normativa-n20-de-21-de-outubro-de-2016-22061778-22061778

Brasil. Ministério da Saúde. Agência Nacional de Vigilância Sanitária-ANVISA. (2001). Resolução RDC $n^{\circ} 12$, de 2 de janeiro de 2001. Aprova Regulamento Técnico sobre Padrões Microbiológicos para Alimentos e seus anexos I e II. Diário Oficial [da] República Federativa do Brasil, Brasília. Recuperado em 15 junho de 2018, de http:// portal.anvisa.gov.br/documents/33880/2568070/ RDC_12_2001.pdf/15ffddf6-3767-4527-bfac$740 \mathrm{a} 0400829 \mathrm{~b}$

Brito, D. A. P., Alves, L. M. C., \& Costa, F. N. (2010). Detecção de Salmonella Albany, Staphylococcus coagulase positivos e micro-organismos mesófilos em carcaças de frango in natura. Instituto Biológico de São Paulo, 77, 149-152. Recuperado em 27 junho de 2019, de http://www.biologico.sp.gov. br/uploads/docs/arq/v77_1/brito.pdf

Caldorin, M., Almeida, I. A. Z. C. D., Peresi, J. T. M., \& Alves, E. C. (2013). Ocorrência de Escherichia coli produtora de toxina Shiga (STEC) no Brasil e sua importância em saúde pública. Boletim Epidemiológico Paulista (Online), 10(110), 4-20. Recuperado em 28 junho de 2019, de http:// periodicos.ses.sp.bvs.br/scielo.php?script $=$ sci arttext\&pid=S1806-42722013000200001\&lng= $\mathrm{p} \& \mathrm{nrm}=\mathrm{iso} \& \mathrm{tlng}=\mathrm{p}$

Caramori Júnior, J. G., Roça, R. D. O., Pinto, J. P. D. A. N., Andreatti Filho, R. L., Mendes, A. A., Padovani, C. R., et al.(2005). Avaliação da presença de Salmonella spp em carcaça de frangos de corte, alimentados com rações com probióticos e prebióticos. Higiene Alimentar, 19(133), 72-78. Recuperado em 15 junho de 2018, de https://www. higienealimentar.com.br/133-2/

Cardoso, A. L. S. P., \& Tessari, E. N. C. (2008). Salmonella na segurança dos alimentos. Biológico, 
70(1), 11-3. Recuperado em 13 junho de 2018, de http://www.biologico.agricultura.sp.gov.br/ uploads/docs/bio/v70_1/cardoso.pdf

Cardoso, A. L. S. P., Castro, A. G. M. D., Tessari, E. N. C., Baldassi, L., \& Pinheiro, E. S. (2005). Pesquisa de Salmonella spp, coliformes totais, coliformes fecais, mesófilos, em carcaças e cortes de frango. Higiene Alimentar, 19(128), 144-150. Recuperado em 15 junho de 2018, de https://www. higienealimentar.com.br/128-2/

Casagrande, M. F. (2016). Quantificação de enterobactérias e Clostridium spp. e detecção molecular de Clostridium perfringens, Escherichia coli e Salmonella spp. em pontos de cadeia produtiva da carne de frango (Tese de doutorado). Faculdade de Ciências Agrárias e Veterinárias, Universidade Estadual Paulista "Julio De Mesquita Filho", Jaboticabal. Recuperado em 28 de junho de 2019, de https://repositorio.unesp.br/handle/11449/135907

Delazari, I. (1998). Aspectos microbiológicos ligados a segurança e qualidade da carcaça de aves. Semana Acadêmica Veterinária, 8, 71-77.

Diniz, S. P. S. S. (2002). Micotoxinas (181 p.). Campinas: Livraria e Editora Rural.

Esmerino, L. A., \& Penteado, F. R. (2010). Avaliação da qualidade microbiológica da carne de frango comercializada no município de Ponta GrossaParaná. Publicatio UEPG: Ciências Biológicas e da Saúde, 17(1), 37-45. Recuperado em 27 de junho 2019, de https://revistas.apps.uepg.br/index. php/biologica/article/view/3446

Freitas, M. F. L., Leão, A. E. D. D. S., Stamford, T. L. M., \& Mota, R. A. (2004). Ocorrência de Staphylococcus aureus em carcaças de frango. Boletim do Centro de Pesquisa de Processamento de Alimentos, 22(2). Recuperado em 27 junho de 2019, de https://revistas.ufpr.br/alimentos/issue/ view/119

Freitas, M. F. L., Mota, R. A., de Oliveira Vilela, S. M., de Sena, M. J., \& Bezerra, R. (2006). Cepas de Staphylococcus spp. isoladas de carcaças de frango comercializadas na cidade do Recife-PE, Brasil. Ciência Animal Brasileira, 2(2), 139-145. Recuperado em 27 junho de 2019, de https://agris.fao. org/agris-search/search.do?recordID=DJ2012046596
Galarz, L. A., Fonseca, G. G., \& Prentice-Hernández, C. (2010). Crescimento microbiano em produtos à base de peito de frango durante simulação da cadeia de abastecimento. Food Science and Technology, 30(4), 870-877. Recuperado em 29 junho de 2019, de https://www.scielo.br/scielo.php?pid=S010120612010000400006\&script=sci_arttext

Gomes, B. C. (2007). Enterococos em amostras de alimentos e águas: avaliação da virulência e do desempenho como indicadores de higiene (Tese de de doutorado). Universidade de São Paulo, São Paulo. Recuperado em 29 junho de 2019, de https://www.teses.usp.br/teses/ disponiveis/9/9131/tde-10102007-105510/publico/ DOUTORADOBRUNACARRERGOMES.pdf

Ingham, S. C., \& Schmidt, D. J. (2000). Alternative indicator bacteria analyses for evaluating the sanitary condition of beef carcasses. Journal of Food Protection, 63(1), 51-55. Recuperado em 29 junho de 2019, de https://meridian.allenpress.com/ jfp/article/63/1/51/167014/Alternative-IndicatorBacteria-Analyses-for

Lourenço, J. V. M., \& Silva, M. J. B. D. (2018). Avaliação da presença de Salmonella spp em carcaças de frango comercializadas no município de Maringá-PR (Artigo científico de conclusão de curso). Centro Universitário de Maringá. Recuperado em 28 junho de 2019, de http://rdu. unicesumar.edu.br/handle/123456789/627

Machado, N., Zapata, J., Vasconcelos, M., \& Barroso, M. (1988). Qualidade microbiológica do frango abatido em estabelecimentos de diferentes portes. Ciência Agronômica, 19(1), 13-18.

Magwedere, K., Dang, H. A., Mills, E. W., Cutter, C. N., Roberts, E. L., \& DebRoy, C. (2013). Incidence of Shiga toxin-producing Escherichia coli strains in beef, pork, chicken, deer, boar, bison, and rabbit retail meat. Journal of Veterinary Diagnostic Investigation, 25(2), 254-258. Recuperado em 28 de junho de 2019, de https://journals.sagepub. com/doi/full/10.1177/1040638713477407

Melo, R. V. V. D. (2016). Qualidade Higiênico Sanitária de carne de frango in natura comercializada no municipio de Santa Cruz/RN (Artigo científico de conclusão de curso). Universidade Federal do Rio Grande do Norte, Santa Cruz. Recuperado em 
28 de junho de 2019, de https://monografias.ufrn. br/jspui/handle/123456789/2396

Menezes, L. D. M., Lima, A. L., Pena, E. C., Silva, G. R., Klein, R. W. T., Silva, C. A., Assis, D. C. S., Figueiredo, T. C., \& Cançado, S. V. (2018). Caracterização microbiológica de carcaças de frangos de corte produzidas no estado de Minas Gerais. Arquivo Brasileiro de Medicina Veterinária e Zootecnia, 70(2), 623-627. Recuperado em 02 fevereiro de 2020, de https://www.scielo.br/scielo. php?pid=S0102-09352018000200623\&script $=$ sci abstract\&tlng $=\mathrm{pt}$

Miyagusku, L., Chen, F., Leitão, M. D. F., \& Baffa, O. (2003). Avaliação microbiológica e sensorial da vida-útil de cortes de peito de frango irradiados. Food Science and Technology, 23, 7-16. Recuperado em 13 junho de 2018, de https://www.scielo.br/scielo.php?pid=S010120612003000400003\&script=sci_arttext

Montezani, E., Giuffrida, R., Andrade, R. A. P., $\&$ Silva, B. L. (2017). Isolamento de Salmonella spp e Staphylococcus aureus em carne de frango e condições dos estabelecimentos comerciais no município de Tupã - SP. Colloquium Vitae, 9(2), 30-36. Recuperado em 13 junho de 2018, de http:// revistas.unoeste.br/index.php/cv/article/view/1314

Oplustil, C. P., Zoccoli, C. M., Tobouti, N. R., $\&$ Sinto, S. I. (2004). Procedimentos básicos em microbiologia clínica (2. ed.). São Paulo: Sarvier Editora.

Pardi, M. C., dos Santos, I. F., de Souza, E. R., \& Pardi, H. S. (1993). Ciência, higiene e tecnologia da carne (Vol. 1). CEGRAF-UFG.

Pereira, M. L., Pereira, J. L., Serrano, A. D. M., \& Bergdoll, M. S. (1999). Estafilococos e alimentos: possibilidades de disseminação através do portador humano e animal. Higiene Alimentar, 13(66-67), 48-55. Recuperado em 27 de junho de 2019, de https://www.higienealimentar.com.br/66-2/

Pimentel, C. N. M., da Costa Godot, T. M., \& Figueiredo, E. L. (2019). Avaliação microbiológica de carne de frango comercializadas no município de Castanhal, Pará/Microbiological evaluation of chicken meat sold in the municipality of Castanhal, Pará. Brazilian Journal of Development, 5(10), 21863-21871. Recuperado em 02 fevereiro de
2020, de http://www.brazilianjournals.com/index. php/BRJD/article/view/4128

Saccomori, F. (2013). Fungos deteriorantes de empanados congelados de frango: isolamento, caracterização e crescimento em baixas temperaturas (Dissertação de mestrado). Universidade Federal de Santa Maria, Santa Maria. Recuperado em 27 junho 2019, de https://repositorio.ufsm.br/ handle/1/5754

Sales, W. B., Berlanda, P. L., Peres, A. P., de Melo Vasco, J. F., \& Caveião, C. (2014). Avaliação microbiológica da carne de frango. Cadernos da Escola de Saúde, 2(12). Recuperado em 27 junho 2019, de https://portaldeperiodicos.unibrasil.com. br/index.php/cadernossaude/article/view/2418

Silva, F. B. D. (2018). Pesquisa de Salmonella spp e Escerichia coli em cortes de frango temperado comercializados no município de Rio Verde, Goiás (Dissertação de mestrado). Universidade Federal de Goiás, Jatai. Recuperado em 28 junho de 2019, de https://repositorio.bc.ufg.br/tede/handle/tede/9188

Silva, J. A., Azerêdo, G. A. D., Barros, C. M., Costa, E. L. D., \& Falcão, M. (2002). Incidência de bactérias patogênicas em carne de frango refrigerada. Higiene Alimentar, 16(100), 97-101. Recuperado em 13 junho de 2018, de https://www. higienealimentar.com.br/100-2/

Silva, K. R., \& Menão, M. C. (2016). Avaliação microbiológica de cortes de frangos comercializados na cidade de São Paulo. Atas de Saúde Ambiental - ASA, 3(2), 17-23. Recuperado em 02 fevereiro de 2020, de http://revistaseletronicas.fmu.br/index. php/ASA/article/view/948

Silva, M. C. D. D., Ramalho, L. S., \& Figueiredo, E. T. D. (2004). Salmonella sp em ovos e carcaças de frango in natura comercializadas em Maceió, AL. Higiene Alimentar, 18(121), 80-84. Recuperado em 29 junho de 2018, de https://www.higienealimentar. com.br/121-2/

Silva, N., Junqueira, V. C. A., Silveira, N. F. A., Taniwaki, M. H., Santos, R. F. S., \& Gomes, R. A. R. (2007). Bacillus cereus. In N. Silva, N., Junqueira, V. C. A., Silveira, N. F. A., Taniwaki, M. H., Gomes, R. A. R., \& Okazaki, M. M. Manual de métodos de análise microbiológica de alimentos (pp. 149-160). São Paulo: Livraria Varela. 
Spoto, M. H. F., Gallo, C. R., Domarco, R. E., Alcarde, A. R., Walder, J. M. M., \& Blumer, L. (1999). Radiação gama na redução da carga microbiana de filés de frango. Food Science and Technology, 19(3), 397-400. Recuperado em 13 junho de 2018, de https://www.scielo.br/scielo. php?pid=S0101-0611999000300018\&script $=$ sci

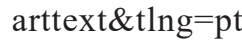

Tessari, E. N. C., Cardoso, A. L. S. P., Kanashiro, A. M. I., Stoppa, G. F. Z., Luciano, R. L., \& Castro, A. G. M. D. (2008). Ocorrência de Salmonella spp. em carcaças de frangos industrialmente processadas, procedentes de explorações industriais do Estado de São Paulo, Brasil. Ciência Rural, 38(9), 2557. 2560. Recuperado em 13 junho de 2018, de https://www.scielo.br/scielo.php?pid=S010384782008005000011 \&script $=$ sci_arttext
Trung, N. V., Nhung, H. N., Carrique-Mas, J. J., Mai, H. H., Tuyen, H. T., Campbell, J., Nhung, N. T., Van Minh, P., Wagenaar, J. A., Mai, N. T. N., Hieu, T. Q., Schultsz, C., \& Hoa, N. T. (2016). Colonization of Enteroaggregative Escherichia coli and Shiga toxin-producing Escherichia coli in chickens and humans in southern Vietnam. BMC Microbiology, 16(1), 208. Recuperado em 28 junho de 2019, de https://link.springer.com/ article/10.1186/s12866-016-0827-z

Zagonel, E. F., Espinola, M. E., Paris, V. D. P. S., \& Gelinski, J. L. N. (2017). Avaliação presuntiva da qualidade higênico-sanitária de coxas e sobrecoxas de frango resfriadas obtidas comercialmente. Anuário Pesquisa e Extensão UNOESC Videira, 2, e13457-e13457. Recuperado em 28 junho de 2019, de https://portalperiodicos.unoesc.edu.br/ apeuv/article/view/13457 